\title{
Consequences of inconsistently classifying woodland birds
}

\author{
Hannah Fraser ${ }^{1 *}$, Georgia E. Garrard ${ }^{2}$, Libby Rumpff ${ }^{1}$, Cindy E. Hauser ${ }^{1}$ and \\ Michael A. McCarthy ${ }^{1}$
}

${ }^{1}$ QAECO Lab, School of BioSciences, University of Melbourne, Melbourne, VIC, Australia, ${ }^{2}$ Interdisciplinary Conservation Science Research Group, Global, Urban and Social Studies, Royal Melbourne Institute of Technology University, Melbourne, VIC, Australia

\section{OPEN ACCESS}

Edited by:

Daniel Sol,

Centre for Ecological Research and Applied Forestries, Spain

Reviewed by:

Laura J. May-Collado,

University of Vermont, USA

Mario Diaz,

Consejo Superior de Investigaciones

Científicas, Spain

*Correspondence:

Hannah Fraser,

School of BioSciences, University of Melbourne, BioSciences 2, Parkville,

VIC 3010, Australia

hannahsfraser@gmail.com

Specialty section:

This article was submitted to

Behavioral and Evolutionary Ecology,

a section of the journal

Frontiers in Ecology and Evolution

Received: 24 December 2014

Accepted: 07 July 2015

Published: 21 July 2015

Citation:

Fraser H, Garrard GE, Rumpff L, Hauser CE and McCarthy MA (2015)

Consequences of inconsistently classifying woodland birds.

Front. Ecol. Evol. 3:83.

doi: 10.3389/fevo.2015.00083
There is a longstanding debate regarding the need for ecology to develop consistent terminology. On one hand, consistent terminology would aid in synthesizing results between studies and ease communication of results. On the other hand, there is no proof that standardizing terminology is necessary and it could limit the scope of research in certain fields. This article is the first to provide evidence that terminology can influence results of ecological studies. We find that researchers are classifying "woodland birds" inconsistently because of their research aims and linguistic uncertainty. Importantly, we show that these inconsistencies introduce a systematic bias to results. We argue that using inconsistent terms can bias the results of studies, thereby harming the field of ecology, because scientific progress relies on the ability to synthesize information from multiple studies.

Keywords: nomenclature, terminology, classification, consistent, standardization, ecological synthesis, woodland bird, woodland-dependent bird

\section{Introduction}

Interpreting language is subjective and inexact. Language can be flexible and meaning is typically attributed to words on the basis of how people use them (Rey, 2005; Temmerman and Van Campenhoudt, 2011). However, sometimes this process results in omnibus terms which have too many meanings to be useful (Peters, 1991; Lindenmayer and Fischer, 2007). Using terms inconsistently can be problematic in scientific papers which must: (a) be replicable and; (b) convey a particular message as intended by the authors (Peters, 1991). From this need for exact terms comes the field of "terminology," concerned with developing specific, universally-acknowledged terms (Pecman, 2014).

Terminologists propose that specialized fields like science, engineering and medicine require consistent language for clear and specific communication of findings (Cabré Castellví, 2003; L'Homme et al., 2003). This need for consistency is particularly pronounced in the medical field, due to the potentially high costs of miscommunication. This has led to the development of manuals guiding the use of medical terms (American Psychiatric Association, 2000; Gray, 2000).

In ecology, there have been sporadic efforts to promote consistency in terminology. In 1931, the Ecological Society of America formed the Committee on Ecological Nomenclature to promote consistent use of terminology by their members (Hanson et al., 1931). Since it disbanded in 1956, there has been little progress toward a consistent terminology in ecology (contra Laporte and Pey, 2014; Laporte and Garnier, 2012). Nevertheless, debate persists in the literature, with some arguing that inconsistent terminology is a problem in ecology (e.g., Peet, 1974; Herrando-Perez et al., 2014), 
and others suggesting that consistent terminology is unnecessary (Hodges, 2008, 2014; Jax and Hodges, 2008).

Calls for the development of a consistent terminology in ecology focus on two primary issues (Mason and Langenheim, 1957; Hall et al., 1997; MacGregor-Fors, 2011). First, ambiguous terms are rife in ecology. Ambiguous terms are those which may be defined in several, often similar, ways (Regan et al., 2002). For example the "cover" of vegetation might be defined as foliage projective cover or crown cover, which are different in practice. Precise definition can reduce ambiguity. The second issue is one of vagueness in classification. Vague terms contain borderline cases in which it is hard to know whether something belongs in one category or another (Regan et al., 2002). For example, discrete categories such as "rare" or "widespread" are commonly used in ecology and related disciplines, but they group complex concepts into restrictive, often arbitrarily divided alternatives. The terms will be used inconsistently if researchers have different understandings of how categories should be distinguished (Jax, 2006).

Inconsistent terminology can slow scientific progress (Herrando-Perez et al., 2014). It can lead to difficulties in finding and compiling relevant studies when reviewing the literature, which may cause redundant scientific investigations, or the inclusion of incomparable studies in a research synthesis (e.g., a meta-analysis) (MacGregor-Fors, 2011; Herrando-Perez et al., 2014). Inconsistent use of terminology can also cause problems when communicating findings to other scientists, policy makers and the public, as results may be misinterpreted or misrepresented due to ambiguous language (MacGregor-Fors, 2011; Herrando-Perez et al., 2014).

On the flipside, some researchers argue against the need for consistent terminology. Hodges (2008) suggests that there is no empirical proof that using terms inconsistently causes meaningful miscommunication in ecology. Furthermore, many authors define key terms in their articles, which minimizes ambiguity. Each individual article can be exact and unambiguous despite the lack of a consistent terminology between studies (Hodges, 2008). Another line of argument proposes that consistent terminology is unnecessary because the intended meaning is clarified by a term's context (Hodges, 2008; Araúz et al., 2013). Lastly, multiple definitions of a term can open a number of fields of enquiry which would have been proscribed by using one concrete definition. Therefore, a greater understanding of a problem might be achieved if it is less precisely defined (Hodges, 2008).

Regardless of arguments for and against a consistent terminology in ecology, there is a lack of empirical evidence to inform this debate. We address this gap by examining the classification of Australian woodland birds. Currently, no strong evidence exists that this group is being classified inconsistently (but see Reid, 1999; Kavanagh et al., 2007; Kinross and Nicol, 2008; Kinross and Nicol, for examples of studies which consider multiple classifications). Nevertheless, inconsistency in findings suggests that some unstudied variation might exist.

The majority of woodland bird articles cite a decline in woodland birds due to habitat destruction and degradation (Rayner et al., 2014a); however, the evidence of this is equivocal.
Some studies show evidence of a decline in woodland birds (e.g., Barrett et al., 2004) while others do not (e.g., Rayner et al., 2014a). There is similar disagreement about whether woodland bird prevalence relates to vegetation extent (Major et al., 2001; Mac Nally and Horrocks, 2002) or fragmentation (Radford et al., 2005; Amos et al., 2013). The disagreement between these studies could be attributed to regional differences (Polyakov et al., 2013), or differences in temporal (Yen et al., 2011) or spatial scale (Lindenmayer et al., 2010), but may also be symptomatic of underlying disagreement about exactly what constitutes a "woodland bird." Deciding how to classify woodland birds raises many questions including: Does this term refer to birds that occur in woodlands and how often do they have to reside in woodlands to count? Do we only include species that nest in woodlands or also those that forage there? What if species only need woodlands for part of their life cycle? The way authors address these questions is often unclear and the species they include as "woodland birds" will differ depending on the answers. Thus, we chose to study inconsistency in the classification of Australian woodland birds for three reasons. First, inconsistency seemed plausible given the lack of classification guidelines and contradictory findings about how woodland birds respond to their habitat. Second, a sufficient body of research existed to obtain meaningful results. Third, any inconsistency has potential policy consequences.

Here, we investigate (i) how consistently researchers are classifying woodland birds, (ii) why inconsistencies are occurring and, most importantly, (iii) how inconsistencies are affecting conclusions about woodland bird ecology and management. We expected that researchers would classify most of the same species as woodland birds, but disagree about a few species that are difficult to classify because they partially depend on woodland vegetation, and are therefore subject to vagueness, or their biology or behavior is poorly understood. We were uncertain whether we would find evidence of substantial differences in the results of studies attributable to the use of different classifications. If so, it would demonstrate that inconsistent classification is impeding researchers fully understanding the ecology and management of woodland birds and that there may be benefit in developing a consistent definition of what constitutes a woodland bird.

\section{Material and Methods}

\section{Investigating Inconsistency in Woodland Bird Classification}

We conducted a systematic review of research about Australian woodland birds using two concurrent methodologies in August 2014. We performed a Google Scholar search using the search terms "woodland birds" and "Australia" and recorded the digital databases that host the first 100 papers. We then performed a thorough search of these databases (Elsevier, Wiley online library, Taylor and Francis, CSIRO, Springer, Royal Society Publishing, PLoS one and JSTOR). To complement this, we also searched the online repositories Scopus and Web of Science. The search terms used in both instances were: "Australia" AND any of (1) 
"woodland bird" OR (2) "woodland dependent" AND "bird" OR (3) "woodland" AND "bird." Articles not based in Australia and those focused on non-avian species or communities, nonwoodland habitats or single or pairs of species were removed. Information about the number of articles found and excluded at each step of this process is presented in Supplementary Material Data Sheet 1. The articles obtained through this search were broken into 5 categories for articles that: (1) mentioned but did not study woodland birds; (2) studied woodland birds but did not specify the species; (3) specified the species they regarded as woodland birds but gave no information about the species which were classed as non-woodland birds; (4) were about a specific group of woodland birds such as "declining woodland birds"; and (5) those which specified both woodland and non-woodland species. We were only interested in lists which included both woodland and non-woodland species to ensure that common birds were classified as woodland species no more frequently than less common species (as would be the case if we included studies which only specified woodland species). When multiple articles used the same dataset and method of classifying woodland species (e.g., Radford et al., 2005; Radford and Bennett, 2007; Garrard et al., 2012), only one list was retained. This search process yielded 38 lists of woodland birds.

For each species we calculated the number of lists containing the species and the percentage of these that classified the species as a woodland bird. This method is subject to variation when there are few records for a particular species. For example, if a species was reported in only one list, it can only have been classified as a woodland species in either 0 or $100 \%$ of studies, which is unlikely to represent the value that might be achieved if more authors considered the species. In order to reduce this variation, those species that were present in 10 or fewer species lists were excluded from further analysis. This left us with data on the classification of 165 species. The frequency distribution of the results was then plotted to illustrate the inconsistency in woodland bird classification.

\section{Testing the Influence of Inconsistent Classification}

To assess the consequences of inconsistent use of the term "woodland bird," we investigated how variation in woodland bird classification affected the findings and interpretation of a published ecological study (Garrard et al., 2012). This study investigates the vulnerability of woodland bird species to habitat fragmentation. The response of woodland birds to habitat fragmentation was the subject of $33 \%$ of the articles returned in our systematic review and, as such, we expect that our investigation is broadly applicable to woodland bird research in Australia.

The methods used by Garrard et al. (2012) and the alterations made to investigate the effect of inconsistent classification are described in Supplementary Material Data Sheet 2. In essence, Garrard et al.'s (2012) study involved two steps. First, they estimated the dispersal ability of a particular set of woodland bird species based on their traits. They then investigated the relationship between this estimate of dispersal ability and the probability of species occurring in landscapes with varying levels of tree cover aggregation, a measure of how clumped together trees are in the landscape which is roughly the inverse of habitat fragmentation (Radford and Bennett, 2007). We investigated the sensitivity of Garrard et al.'s findings about the relationship between dispersal ability and response to tree cover aggregation by simulating the effect of choosing different sets species to represent woodland birds, based on the percentage of studies in which species were classified as woodland birds.

Some authors consider all species present in woodlands to be woodland birds, while others have more stringent criteria. Therefore, we analyzed the effect of increasingly stringent classification criteria on the response of the Garrard et al. (2012) model (Supplementary Material Data Sheet 2). We ran the model 9 times on different sets of species, one which included all species, and 8 representing frequency thresholds of $10,20,30 \ldots 80 \%$ to simulate the effect of becoming more selective about which species are included as woodland birds. So, the list based on the $80 \%$ frequency threshold only included those species that are classified as woodland birds in $80 \%$ or more of lists. The list based on the $70 \%$ frequency threshold included the same species, but also those that classified as woodland birds in $70-80 \%$ of lists, and so on. The results of each model run are not independent but further analyses show that this does not affect our overall result (Supplementary Material Data Sheet 3).

We examined how the estimate of the mean species response to tree cover aggregation for each of these nested subsets compared with the original estimate from Garrard et al. (2012) to determine how classification inconsistency might influence ecological inference. Garrard et al.'s study used a subset of data collected in an earlier study (Radford et al., 2005). In our study, we included all species found during the original survey; we estimated the median dispersal distance of the species not included by Garrard et al. (2012) using the dispersal model presented in their study (Supplementary Material Data Sheet 2).

\section{Reasons for Inconsistency in Woodland Bird Classification}

We were interested in understanding the reasons for inconsistency in classification. In particular, we were interested in: (1) how well recognized lack of consistency was in the research community; (2) why researchers were classifying species differently; and (3) whether researchers thought inconsistent classification was problematic. We emailed the authors $(n=131)$ of the 109 papers collected in the systematic review to invite them to participate in our survey. They were presented with the findings of the systematic review and a value representing how consistent the lists they used in their studies were with other research. They were then asked a series of questions via SurveyMonkey (Survey Monkey Inc, 1999) regarding how they classify woodland birds and woodlands, and their views on why researchers may be classifying species differently (a copy of the survey is available in Supplementary Material Data Sheet 4). Authors received up to 4 emailed reminders to prompt them to fill in the survey. Of the 131 authors we contacted, 69 completed the survey, 31 responded to say that they were not involved in the woodland bird aspects of the study, and 31 did not respond. 
Survey questions came under four main headings: experience, beliefs about classification consistency, how woodland vegetation and birds are classified, and why the classifications are different between studies. The experience section was intended to allow us to exclude answers given by people who had never been involved in classifying woodland birds and therefore were unable to meaningfully answer some of the questions. In the section on beliefs about classification consistency, experts were asked whether they agreed that some research questions required different lists of woodland birds, and whether using a standardized list would be detrimental to answering certain research questions. The next section asked them to select the criteria that they used to distinguish woodland vegetation, and woodland birds. In the section about why classifications differ between studies, experts were asked to rate, on a scale of 1-10, how much they believe each option contributed to differences in the classification of woodland birds. In order to collect quantitative information, answers to the majority of questions were given via multiple choice options $(n=6)$ or Likert scales $(n=2)$. The options posed in the multiple choice questions were drawn from definitions of woodlands and woodland birds found in the systematic review articles.

\section{Results}

\section{Systematic Review}

Of the articles reviewed, 7 mentioned but did not study woodland birds, 32 studied woodland birds but did not specify the species, 28 specified the species they regarded as woodland birds but gave no information about the species which were classed as nonwoodland birds, 15 were about a specific group of woodland birds such as "declining woodland birds," and 38 specified both woodland and non-woodland species. These 38 lists formed the basis of the analyses. Only including studies specifying woodland and non-woodland species avoids confounding species that are "non-woodland birds" with those "woodland birds" which were absent from the survey.

In total, 165 bird species were recorded in at least 10 of the lists examined by this study. Excluding species that were in fewer than 10 lists tended to exclude more species from water-dependent and uncommon orders of birds (details about the classification of species are supplied in Supplementary Material Data Sheet 5). Of the 165 species, 8 were recorded as woodland birds in every list and 13 species were always classified as non-woodland birds. The remaining 144 species were inconsistently classified at least once (Figure 1).

The bimodal frequency distribution represented in Figure 1 indicates that there is agreement regarding the classification of a substantial proportion of species, but that this is not unanimous and there is little certainty in the classification of many species.

\section{Effects of Inconsistency}

The data collected by Radford et al. (2005) and used for Garrard et al. (2012) comprised 126 species. When all species found during the original field surveys were included in the analysis, the predicted effect of landscape aggregation on prevalence was 3.0 (Figure 2; 95\% credible interval 2.1-3.9). This is substantially smaller than the effect size estimated by Garrard et al. (2012), who estimated the mean effect of habitat aggregation (variable br in Supplementary Material Data Sheet 2) to be 5.9 with $95 \%$ credible intervals of 4.2-8.2. The effect sizes estimated from the other subsets of data increased with increasing frequency thresholds such that the $80 \%$ threshold yielded an effect of 6.1 (95\% credible interval 4.5-7.6; Figure 2).

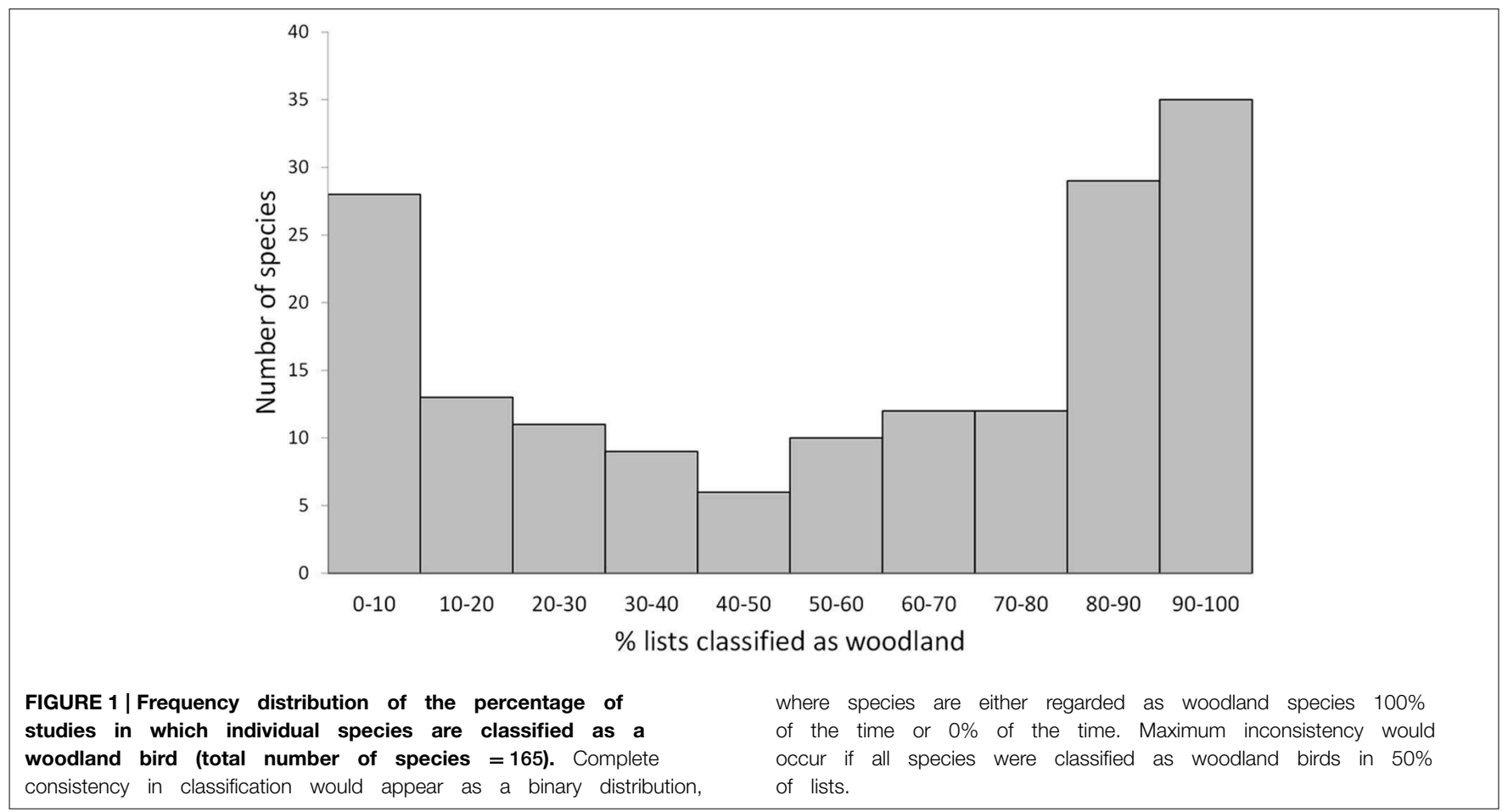




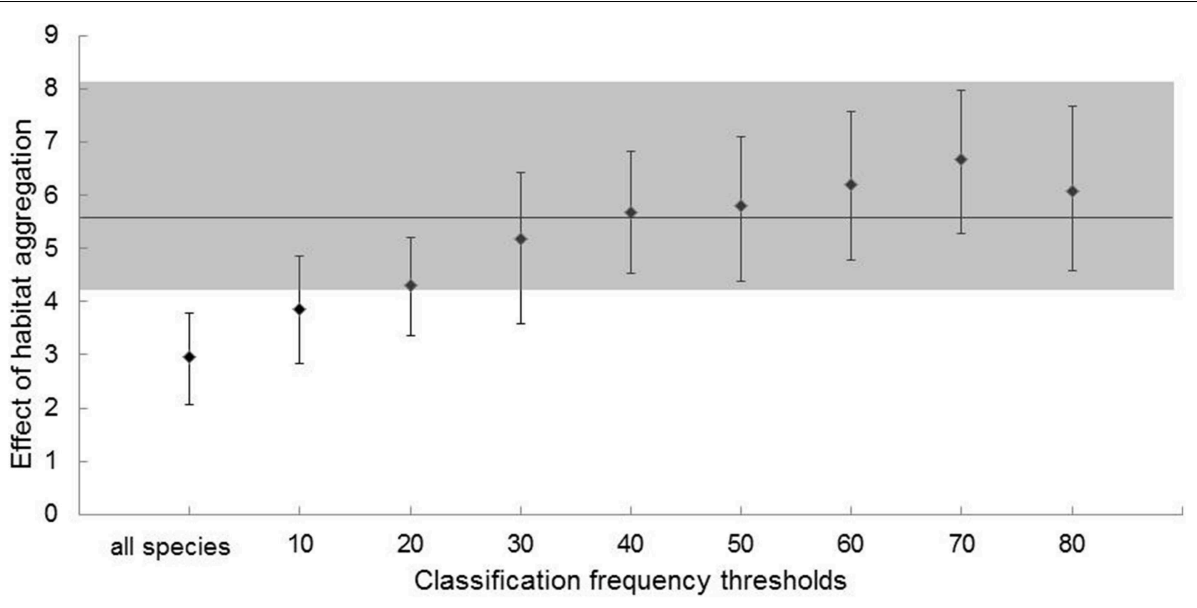

FIGURE 2 | The predicted effect of tree cover aggregation on species prevalence, for different subsets of species representing frequency thresholds of $\mathbf{1 0}, \mathbf{2 0}, \mathbf{3 0}, \ldots \mathbf{8 0} \%$. At 80 on the horizontal axis, only species which are regarded as woodland birds in $80 \%$ or more of studies are included in the model. Error bars represent 95\% credible intervals. Mean estimate from the original, Garrard et al. (2012) model is represented by the line and the $95 \%$ credible intervals by the gray shaded area.
TABLE 1 | The number of respondents (out of 69) selecting different factors as influencing the way they classify vegetation as woodland.

\begin{tabular}{llc}
\hline & Option & $\begin{array}{c}\text { Number of responses } \\
\text { ( } \boldsymbol{n}=69)\end{array}$ \\
\hline Tree characteristics & Presence of trees & 54 \\
& Tree density & 50 \\
& Canopy cover & 46 \\
& Tree height & 36 \\
& Tree species & 35 \\
& Any tree characteristic & 67 \\
\hline Shrub characteristics & Shrub species & 7 \\
& Shrub cover & 6 \\
& Presence of shrubs & 9 \\
Soil properties & Any shrub characteristic & 15 \\
Ecological Vegetation Class: woodland & 2 \\
\hline
\end{tabular}

These factors are broken into shrub, tree and other categories to give a clear indication of how important they each were for determining whether vegetation is "woodland." The number of respondents listing each factor is given as well as the number of respondents listing any factor within the shrub and tree categories.

\section{Survey Results}

In total, 69 woodland bird experts filled in the survey. All researchers acknowledged that they list woodland birds differently to each other but the vast majority $(n=55$, $80 \%$ ) believe that using different lists of woodland birds is not problematic for ecological research (item 9 of survey). In fact, 39 (of $68,57 \%$ ) experts believed that it would be problematic to have a unified list of woodland species because it would hinder the investigation of certain research questions (item 4).

The survey identified vagaries in the definition of woodland vegetation as a key reason for inconsistency of woodland bird classification (items 6 and 7). Researchers variously listed between 1 and 9 factors that affected the way they classified woodland vegetation. The majority of responses $(n=67$,
97\%) included a characteristic of trees, with a lesser number specifying that their classification was based on ecological vegetation classes or other similar systems $(n=23$, $33 \%)$ or characteristics of shrubs (Table 1). Very few experts $(n=2,3 \%)$ considered soil properties when classifying woodlands.

Researchers listed between 1 and 9 factors as contributing to their classification of species as woodland birds (item 5). Of the 14 options, all were selected at least once. The majority ( $n=60,87 \%)$ of experts considered occurrence when classifying woodland birds, and a substantial number of experts based their classification on traits $(n=57,83 \%)$ or used an authorized classification such as one used in a field guide or journal article $(n=39,57 \%)$ (Table 2). There was also widespread use of exclusion criteria such as whether a species was nocturnal or a water bird $(n=25,36 \%)$.

Authors were asked to rate possible reasons for inconsistencies between researchers (item 7) and those that ranked the highest were A) "different ideas about how to determine whether species rely on woodland vegetation," (B) "different aims of research" and (C) "regional differences in the behavior or habitat requirements" and (D) "regional differences in the distribution of species" (Figure 3). Uncertainty about the behavior or habitat requirements $(\mathrm{G})$ and distribution of species (F) ranked relatively low.

\section{Discussion}

The need for ecological terms to be classified consistently is disputed in the literature, and this is reflected in the responses to our survey. Although the surveyed experts were aware that the term "woodland bird" was being used to represent different sets of species, almost all thought the inconsistency was not problematic $(n=55$ of 69$)$. Over half of experts $(n=39$ of 68) felt that conforming to a consistent definition would inhibit their ability to answer certain research questions, although many ( $n=29$ of 68$)$ did not. This belief is consistent with Hodges' 
TABLE 2 | The number of respondents (out of 69) selecting different factors as influencing the way they classify species as woodland birds.

\begin{tabular}{|c|c|c|}
\hline & Option & $\begin{array}{l}\text { Number of responses } \\
\qquad(n=69)\end{array}$ \\
\hline \multirow[t]{3}{*}{ Occurrence based } & Present in woodlands & 43 \\
\hline & $\begin{array}{l}\text { Occurs more frequently in } \\
\text { woodlands than in other } \\
\text { habitats }\end{array}$ & 55 \\
\hline & Any occurrence based metric & 60 \\
\hline \multirow[t]{3}{*}{ Authorized classification } & $\begin{array}{l}\text { Classified as a woodland bird } \\
\text { by another author }\end{array}$ & 38 \\
\hline & $\begin{array}{l}\text { Classified as a woodland bird } \\
\text { in a field guide/bird } \\
\text { handbook }\end{array}$ & 18 \\
\hline & Any authorized classification & 39 \\
\hline \multirow[t]{4}{*}{ Trait based } & Nests in woodlands & 55 \\
\hline & Forages in woodlands & 50 \\
\hline & Shelters in woodlands & 41 \\
\hline & Any trait based metric & 57 \\
\hline \multirow[t]{4}{*}{ Habitat associations } & $\begin{array}{l}\text { Intolerant of degraded sites } \\
\text { (e.g., grazed sites) }\end{array}$ & 4 \\
\hline & Intolerant of fragmented sites & 1 \\
\hline & $\begin{array}{l}\text { Prefers large areas of } \\
\text { vegetation }\end{array}$ & 6 \\
\hline & $\begin{array}{l}\text { Any habitat association } \\
\text { option }\end{array}$ & 8 \\
\hline \multirow[t]{5}{*}{ Exclusion criteria } & Not wetland & 16 \\
\hline & Not an introduced species & 11 \\
\hline & Not nocturnal & 3 \\
\hline & Not a raptor & 4 \\
\hline & Any exclusion criteria & 25 \\
\hline
\end{tabular}

These factors are classed by underlying orientation into 5 classes: occurrence based, authorized classification, trait based, based on habitat associations and on exclusion criteria. As in Table 1, the number of respondents listing each factor is given as well as the number of respondents listing any factor within the 5 classes.

(2008) assertion that retaining flexibility in definitions of terms can allow a subject to be more fully explored. The results of our study highlight the trade-off between using flexible terminology for woodland birds, allowing researchers to fully explore nuanced research questions, and using standardized terminology, which facilitates generalizing across studies and improves clarity in communication.

Given the lack of evidence for standardization and the benefits of retaining flexibility, it is unsurprising to find inconsistency in ecological terms such as "woodland bird." Prior to our study, Hodges (2008) suggested there was no compelling evidence that consistent terminology is necessary in ecology. However, our study provides evidence that using terms inconsistently can be problematic, both for ecological inference and conservation. In the case of woodland birds, results changed markedly depending on the way the term "woodland birds" is defined, hindering comparison or synthesis of findings from different studies
(Peters, 1991; MacGregor-Fors, 2011; Herrando-Perez et al. 2014).

We demonstrated that results could vary substantially depending on which definition of woodland bird the author considers. In the model developed by Garrard et al. (2012), we found that the effect of tree aggregation on the occurrence of woodland birds varies substantially depending on the species included in the definition of a "woodland bird." This is a clear demonstration that results from different studies are not necessarily comparable.

Importantly, the variation in findings attributed to inconsistent classification may also have direct management implications. The belief that tree cover aggregation has little effect on "woodland bird" occurrence may alter where revegetation or reserves are located in the landscape. Furthermore, the Victorian temperate-woodland bird community is protected under the Flora and Fauna Guarantee Act (Victorian Government, 2013) but the species included in this list are only a subset of the species which authors frequently consider as woodland birds (Supplementary Material Data Sheet 6). Our results demonstrate that researchers use the term "woodland bird" to refer to substantially different sets of birds, and have variable ideas about how this group of species should be identified. Researchers variously categorized "woodland birds" depending on their occurrence, their traits, their habitat associations, on authorized classifications or by using exclusion criteria. This inconsistent classification is a result of both linguistic vagueness (it is unclear where on the continuum of dependence on woodlands that a species becomes a "woodland bird") and ambiguity (it may have more than one meaning, such as "birds that occur in woodlands," "birds that do not occur outside woodlands" or "birds that nest in woodlands") (Regan et al., 2002). This variation is unrecognized in literature reviews (Bennett and Watson, 2011; Ford, 2011), meta-analyses (Maron et al., 2011; Rayner et al., 2014b) and management recommendations (Paton and O'Connor, 2010). Researchers are thus combining information from studies that consider widely different sets of species, confusing the understanding of woodland bird ecology and management, and inhibiting the generalizability of their results.

This brings us to our core questions: does the uncertainty surrounding the term "woodland bird" actually matter? In this case, and in ecology more broadly, is it necessary to consistently define terms to understand ecological relationships and avoid misunderstandings and difficulties in the development of metaanalyses, literature reviews and management recommendations? Is the trade-off between flexible and standardized definitions of terms worth making?

Our findings demonstrate that the magnitude of an effect can depend on how the term "woodland bird" is defined. If two different researchers conducted the same study using the same data but different definitions of "woodland bird," they might develop incongruent or even contradictory results. This is problematic when attempting to understand woodland bird ecology or predict how they will respond to land management. Only a small subset of woodland bird research uses identical lists of "woodland birds," so researchers must choose between including information from many studies (which risks 


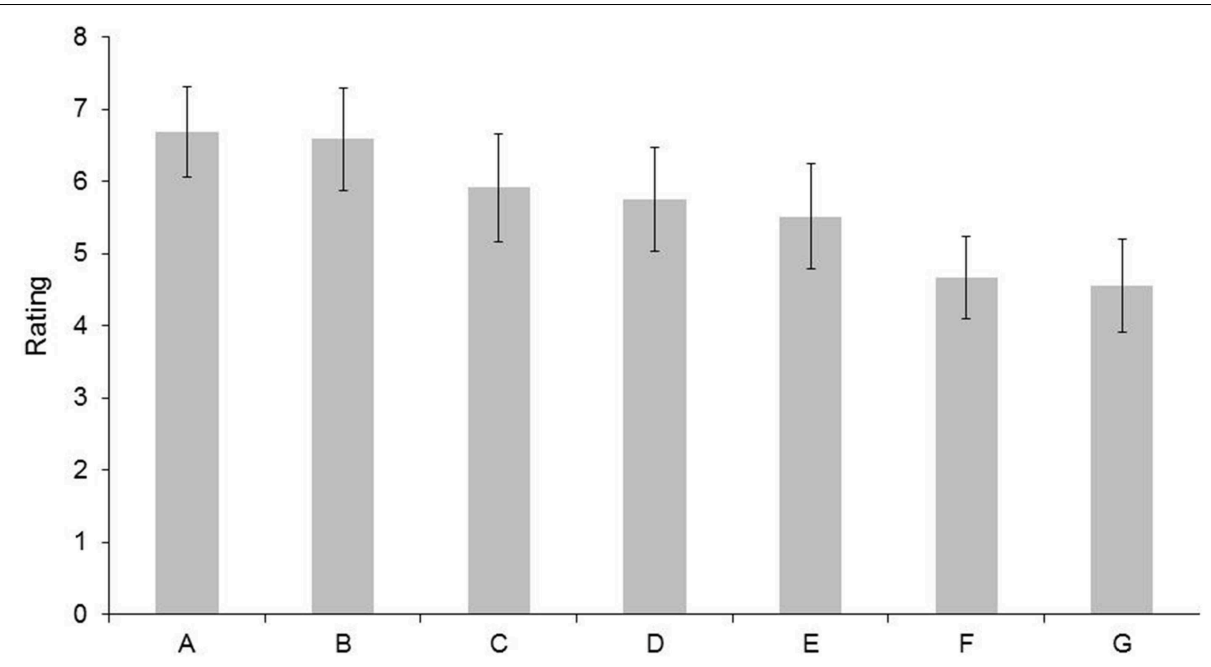

FIGURE 3 | Ratings assigned to each of 7 reasons that researchers use different lists to classify woodland birds. (A) different ideas about how to determine whether species rely on woodland vegetation, (B) different aims of research, $(C)$ regional differences in the distribution of species in woodland and non-woodland areas, (D) regional differences in the behavior or habitat requirements of species, (E) different ideas about what constitutes woodland vegetation, $(F)$ uncertainty about the distribution of the species in woodland and non-woodland areas, (G) uncertainty about the behavior or habitat requirements of different species. Error bars represent the 95\% confidence intervals of the estimates. terminological differences confounding results) or only including studies which use the same definition and list of "woodland birds" (which risks excluding valuable insights from other studies).

However, it is possible that standardizing the definition of "woodland birds" would make it more difficult to answer important ecological questions, as reflected in the responses of 39 (57\%) respondents. The empirical results of this study, which show that classifying woodland birds consistently is important, conflict with the opinions of those experts who believe that standardizing the term "woodland bird" is unnecessary and possibly detrimental.Clearly, there is a trade-off between using flexible definitions of terms and standardizing terms.

Our research provides some of the first empirical evidence that using terms inconsistently in ecology is problematic and needs to be resolved. More research is required to examine whether this effect is widespread but we propose that ecologists need to carefully consider whether they are using terms consistently. Contrary to the argument that inconsistency in classification is not an issue in ecology because terms are context-specific and well-defined by authors (Hodges, 2008), we found that many studies either do not define the term "woodland birds," or define it incompletely. We support an approach which increases the transparency of woodland bird research by making overt the species which are considered "woodland birds," and detailing why they were classified accordingly. Beyond this, we believe that developing standardized definitions of key terms is vital to ecological research and management. When it comes to classifying ecological groups (such as woodland birds) we need to develop terms that have management relevance and, ideally, are based on ecological theory and empirical data. However, we recognize that standardizing terminology may come at a cost in terms of the flexibility of research. Therefore, we propose that, when the research question would be impeded by a standardized terminology, researchers either avoid using the term by studying species individually or using quantitative estimates of traits and habitat associations, or present their results alongside results achieved with the standardized terminology. This would allow flexibility to be maintained but also retain generalizability between studies.

\section{Acknowledgments}

This research is supported by the Australian Research Council (ARC) Centre of Excellence for Environmental Decisions and the National Environmental Research Program Environmental Decisions hub. MM is supported by an ARC Future Fellowship. LR is supported by ARC LP110100321. GG is supported by The Myer Foundation. We would like to thank Jim Radford and Andrew Bennett for species occurrence and landscape data, Gary Luck for the use of his database to re-run the Garrard et al. model, and the woodland bird experts who graciously gave up their time to contribute their views and knowledge to this work. Ethics approval for the consultation of woodland bird experts was provided by the University of Melbourne Humanities and Applied Sciences ethics committee (ethics ID 1340594).

\section{Supplementary Material}

The Supplementary Material for this article can be found online at: http://journal.frontiersin.org/article/10.3389/fevo. 2015.00083 


\section{References}

Amos, J. N., Balasubramaniam, S., Grootendorst, L., Harrisson, K. A., Lill, A., Mac Nally, R., et al. (2013). Little evidence that condition, stress indicators, sex ratio, or homozygosity are related to landscape or habitat attributes in declining woodland birds. J. Avian Biol. 44, 045-054. doi: 10.1111/j.1600048X.2012.05746.x

Araúz, P. L., Reimerink, A., and García-Aragón, A. (2013). Dynamism and context in specialized knowledge. Terminology 19, 31-61. doi: 10.1075/term.19.1.02leo

Barrett, G. W., Silcocks, A. F., Cunningham, R., Oliver, D. L., Weston, M. A., and Baker, J. (2004). Comparison of atlas data to determine the conservation status of bird species in New South Wales, with an emphasis on woodland-dependent species. Aust. Zool. 34, 37-77. doi: 10.7882/AZ.2007.003

Bennett, A. F., and Watson, D. M. (2011). Declining woodland birds- is our science making a difference? Emu 111, i-vi. doi: 10.1071/MUv111n1_ED

Cabré Castellví, M. T. (2003). Theories of terminology: their description, prescription and explanation. Terminology 9, 163-199. doi: 10.1075/term.9.2.03cab

Ford, H. A. (2011). Twinkling lights or turning down the dimmer switch? Are there two patterns of extinction debt in fragmented landscapes? Pacific 17, 303-309. doi: 10.1071/PC110303

Garrard, G. E., McCarthy, M. A., Vesk, P. A., Radford, J. Q., and Bennett, A. F. (2012). A predictive model of avian natal dispersal distance provides prior information for investigating response to landscape change. J. Anim. Ecol. 81, 14-23. doi: 10.1111/j.1365-2656.2011.01891.x

Gray, H. (2000). Anatomy of the Human Body, 20th Edn. Philadelphia: Lea \& Febiger, 1918: Bartleby.com.

Hall, L. S., Krausman, P. R., and Morrison, M. L. (1997). The habitat concept and a plea for standard terminology. Wildl. Soc. Bull. 25, 173-182.

Hanson, H. C., Needham, J. G., Taylor, W. P., Vestal, A. G., and Allen, W. E. (1931). Ecological nomenclature. Science 74, 648-649. doi: 10.1126/science.74.1930.648

Herrando-Perez, S., Brook, B. W., and Bradshaw, C. J. A. (2014). Ecology needs a convention of nomenclature. Bioscience 64, 311-321. doi: 10.1093/biosci/biu013

Hodges, K. E. (2008). Defining the problem: terminology and progress in ecology. Front. Ecol. Environ. 6, 35-42. doi: 10.1890/060108

Hodges, K. E. (2014). Clarity in ecology: terminological prescription is the wrong route. Bioscience 64, 373. doi: 10.1093/biosci/biu049

Survey Monkey Inc. (1999). SurveyMonkey. Available online at: www. surveymonkey.com [Accessed January 1, 2014].

Jax, K. (2006). Ecological units: definitions and applications. Q. Rev. Biol. 81, 237-258. doi: 10.1086/506237

Jax, K., and Hodges, K. E. (2008). Concepts, not terms. Front. Ecol. Environ. 6, 178-179. doi: 10.1890/1540-9295(2008)6[178b:CNT]2.0.CO;2

Kavanagh, R. P., Stanton, M. A., and Herring, M. W. (2007). Eucalypt plantings on farms benefit woodland birds in south-eastern Australia. Austral Ecol. 32, 635-650. doi: 10.1111/j.1442-9993.2007.01746.x

Kinross, C., and Nicol, H. (2008). Responses of birds to the characteristics of farm windbreaks in central New South Wales, Australia. Emu 108, 139. doi: 10.1071/MU06024

L'Homme, M.-C., Heid, U., and Sager, J. C. (2003). Terminology during the past decade (1994-2004): an editorial statement. Terminology 9, 151-161. doi: 10.1075/term.9.2.02hom

Laporte, M.-A., and Garnier, E. (2012). ThesauForm-Traits: a web based collaborative tool to develop a thesaurus for plant functional diversity research. Ecol. Inform. 11, 34-44. doi: 10.1016/j.ecoinf.2012.04.004

Laporte, M.-A., and Pey, B. (2014). ThesauForm - T-SITA: Thesaurus for Soil Invertebrate Trait-based Approaches. Available online at: http://t-sita.cesab.org/ Thesauform/BETSI_vizIndex.jsp [Accessed August 1, 2014].

Lindenmayer, D. B., and Fischer, J. (2007). Tackling the habitat fragmentation panchreston. Trends Ecol. Evol. 22, 127-132. doi: 10.1016/j.tree.2006. 11.006

Lindenmayer, D. B., Knight, E. J., Crane, M. J., Montague-Drake, R., Michael, D. R., and MacGregor, C. I. (2010). What makes an effective restoration planting for woodland birds? Biol. Conserv. 143, 289-301. doi: 10.1016/j.biocon.2009. 10.010

MacGregor-Fors, I. (2011). Misconceptions or misunderstandings? On the standardization of basic terms and definitions in urban ecology. Landsc. Urban Plann. 100, 347-349. doi: 10.1016/j.landurbplan.2011.01.013
Mac Nally, R., and Horrocks, G. (2002). Relative influences of patch, landscape and historical factors on birds in an Australian fragmented landscape. J. Biogeogr. 29, 395-410. doi: 10.1046/j.1365-2699.2002.00682.x

Major, R. E., Christie, F. J., and Gowing, G. (2001). Influence of remnant and landscape attributes on Australian woodland bird communities. Biol. Conserv. 102, 47-66. doi: 10.1016/S0006-3207(01)00090-8

Maron, M. A., Main, A. A., Bowen, M. A., Howes, A. A., Kath, J. C., and Pillette, C. A. (2011). Relative influence of habitat modification and interspecific competition on woodland bird assemblages in eastern Australia. Landsc. Ecol. 111, 40-51. doi: 10.1071/mu09108

Mason, H. L., and Langenheim, J. H. (1957). Language analysis and the concept “environment." Ecology 38, 325-340. doi: 10.2307/1931693

Paton, D., and O'Connor, J. (2010). The state of Australia's birds 2009: restoring woodland habitats for birds. Wingspan 20(Suppl. 1-8).

Pecman, M. (2014). Variation as a cognitive device: how scientists construct knowledge through term formation. Terminology 20, 1-24. doi: 10.1075/term.20.1.01pec

Peet, R. K. (1974). The measurement of species diversity. Annu. Rev. Ecol. Syst. 5, 285-307. doi: 10.1146/annurev.es.05.110174.001441

Peters, R. (1991). A Critique for Ecology. Cambridge, UK: Cambridge University Press.

Polyakov, M., Rowles, A. D., Radford, J. Q., Bennett, A. F., Park, G., Roberts, A., et al. (2013). Using habitat extent and composition to predict the occurrence of woodland birds in fragmented landscapes. Landsc. Ecol. 28, 329-341. doi: 10.1007/s10980-012-9831-3

American Psychiatric Association. (2000). Diagnostic and Statistical Manual of Mental Disorders, 4th Edn. Washington, DC: American Psychiatric Press.

Radford, J. Q., and Bennett, A. F. (2007). The relative importance of landscape properties for woodland birds in agricultural environments. J. Appl. Ecol. 44, 737-747. doi: 10.1111/j.1365-2664.2007.01327.x

Radford, J. Q., Bennett, A. F., and Cheers, G. J. (2005). Landscape-level thresholds of habitat cover for woodland-dependent birds. Biol. Conserv. 124, 317-337. doi: 10.1016/j.biocon.2005.01.039

Rayner, L., Lindenmayer, D. B., Gibbons, P., and Manning, A. D. (2014a). Evaluating empirical evidence for decline in temperate woodland birds: a nationally threatened assemblage of species. Biol. Conserv. 171, 145-155. doi: 10.1016/j.biocon.2014.01.029

Rayner, L., Lindenmayer, D. B., Wood, J. T., Gibbons, P., and Manning, A. D. (2014b). Are protected areas maintaining bird diversity? Ecography 37, 43-53. doi: 10.1111/j.1600-0587.2013.00388.x

Regan, H. M., Colyvan, M., and Burgman, M. (2002). A taxonomy and treatment of uncertainty for ecology and conservation biology. Ecol. Appl. 12, 618-628. doi: 10.1890/1051-0761(2002)012[0618:ATATOU]2.0.CO;2

Reid, J. R. W. (1999). Threatened and Declining Birds in the New South Wales Sheep-wheat Belt: ii. Landscape Relationships-modelling Bird Atlas Data Against Vegetation Cover. Canberra: CSIRO Windlife and Ecology.

Rey, A. (2005). The concept of neologism and the evolution of terminologies in individual languages. Terminology 11,311-331. doi: 10.1075/term.11.2.07rey

Temmerman, R., and Van Campenhoudt, M. (2011). The dynamics of terms in specialized communication: an interdisciplinary perspective. Terminology 17, 1-8. doi: 10.1075/term.17.1.01tem

Victorian Government. (2013). Flora and Fauna Guarantee Act 1988 - Threatened List. Melbourne: The State of Victoria.

Yen, J. D. L., Thomson, J. R., Vesk, P. A., and Mac Nally, R. (2011). To what are woodland birds responding? Inference on relative importance of in-site habitat variables using several ensemble habitat modelling techniques. Ecography 34, 946-954. doi: 10.1111/j.1600-0587.2011.06651.x

Conflict of Interest Statement: The authors declare that the research was conducted in the absence of any commercial or financial relationships that could be construed as a potential conflict of interest.

Copyright (C) 2015 Fraser, Garrard, Rumpff, Hauser and McCarthy. This is an openaccess article distributed under the terms of the Creative Commons Attribution License (CC BY). The use, distribution or reproduction in other forums is permitted, provided the original author(s) or licensor are credited and that the original publication in this journal is cited, in accordance with accepted academic practice. No use, distribution or reproduction is permitted which does not comply with these terms. 